\title{
Salivary Gland Canalicular Adenoma
}

National Cancer Institute

\section{Source}

National Cancer Institute. Salivary Gland Canalicular Adenoma. NCI Thesaurus. Code C5979.

A benign epithelial neoplasm primarily composed of branching and interconnecting cords of single and double-cell thick rows of columnar epithelium in a very loose stroma. It often occurs in the upper lip, where only pleomorphic adenoma is more frequent. Asymptomatic swelling of the upper lip is the most common clinical finding. It may present clinically and histologically as a multifocal lesion, a feature not generally seen with other intraoral salivary gland tumors. 